\title{
Sales of healthy snacks and beverages following the implementation of healthy vending standards in City of Philadelphia vending machines
}

\author{
Meagan L Pharis ${ }^{1, *}$, Lisa Colby ${ }^{2}$, Amanda Wagner ${ }^{1}$ and Giridhar Mallya ${ }^{3}$ \\ ${ }^{1}$ Philadelphia Department of Public Health, 1401 JFK Blvd, Suite 600, Philadelphia, PA 19102, USA: ²Dartmouth \\ Medical School, Lebanon, NH, USA: ${ }^{3}$ Robert Wood Johnson Foundation, Princeton, NJ, USA
}

Submitted 2 December 2016: Final revision received 3 May 2017: Accepted 22 June 2017: First published online 24 October 2017

\begin{abstract}
Objective: We examined outcomes following the implementation of employerwide vending standards, designed to increase healthy snack and beverage options, on the proportion of healthy $v$. less healthy sales, sales volume and revenue for snack and beverage vending machines.

Design: A single-arm evaluation of a policy utilizing monthly sales volume and revenue data provided by the contracted vendor during baseline, machine conversion and post-conversion time periods. Study time periods are full calendar years unless otherwise noted.

Setting: Property owned or leased by the City of Philadelphia, USA.

Subjects: Approximately 250 vending machines over a 4-year period (2010-2013).

Results: At post-conversion, the proportion of sales attributable to healthy items was $40 \%$ for snacks and $46 \%$ for beverages. Healthy snack sales were $323 \%$ higher (38.4 to 162.5 items sold per machine per month) and total snack sales were $17 \%$ lower ( $486 \cdot 8$ to $402 \cdot 1$ items sold per machine per month). Healthy beverage sales were $33 \%$ higher (68.2 to 90.6 items sold per machine per month) and there was no significant change in total beverage sales (213.2 to $209 \cdot 6$ items sold per machine per month). Revenue was $11 \%$ lower for snacks (\$US 468.30 to \$US 415.70 per machine per month) and $21 \%$ lower for beverages (\$US 344.00 to \$US $270 \cdot 70$ per machine per month).

Conclusions: Sales of healthy vending items were significantly higher following the implementation of employer-wide vending standards for snack and beverage vending machines. Entities receiving revenue-based commission payments from vending machines should employ strategies to minimize potential revenue losses.
\end{abstract}

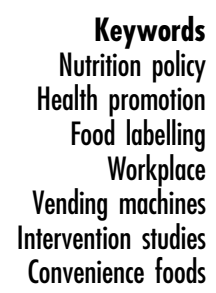

Policy is an important tool in population-wide health promotion and obesity prevention. One role of policy interventions is to alter the default environmental conditions that contribute to obesity ${ }^{(1)}$. Worksites are part of the food environment for most adults, therefore interventions in this setting have the potential to improve dietary intake at the population level ${ }^{(2)}$. Public health departments are uniquely positioned to implement changes in the worksites of public employees and for visitors to public facilities. Vending machines typically offer limited healthy choices, providing an opportunity for environmental interventions by changing the products available through vending machines ${ }^{(3-5)}$.

Several government agencies in the USA have implemented vending standards designed to offer healthier choices in government settings. The Chicago Parks District implemented system-wide vending standards in 2011 and found strong patron and staff approval and increases in sales over time ${ }^{(6)}$. A 2011 mayoral executive order in Boston successfully increased the proportion of healthy beverages offered through vending machines, and a pilot healthy vending programme in Delaware State Agency buildings showed positive results ${ }^{(7,8)}$. New York City, San Francisco and Annapolis have also implemented vending standards designed to promote healthier options on city property ${ }^{(9-11)}$.

Healthy vending initiatives have led to increased sales of healthy vending items, increased sales of lower-energy items and reductions in unhealthy nutrient content, all without decreasing total sales volumes ${ }^{(12-16)}$. Results, though, have varied based on the nature of standards (complete elimination of certain less healthy items, like sugary drinks, $v$. changing the mix of healthy and less 
healthy products) and the inclusion of modifications to price and/or promotion ${ }^{(12-17)}$.

In 2011, the Philadelphia Department of Public Health (PDPH) developed healthy vending standards for over 300 beverage and snack vending machines accessible to 26000 City employees and the public on property owned or leased by the City of Philadelphia, including city buildings, libraries, recreation centres, police stations, correctional facilities and courts. The purpose of the present study was twofold: (i) to examine the proportion of healthy $v$. less healthy units sold; and (ii) to evaluate the sales volume of beverage and snack vending machines before, during and after policy implementation.

\section{Methods}

\section{Vending standards}

Philadelphia is a racially and ethnically diverse city (44\% Black, $45 \%$ White, $14 \%$ Hispanic, and $7 \%$ Asian $)^{(18)}$. Of the approximately 1.5 million residents, about one in four $(25.8 \%)$ is below the federal poverty level and one in three adults (33.3\%) is obese ${ }^{(19)}$. In 2010, PDPH launched the Get Healthy Philly initiative to promote healthy eating, active living and smoke-free lifestyles through policy, systems and environmental change ${ }^{(20)}$. In January 2011, Get Healthy Philly partnered with the Procurement Department and the City's contracted vending agencies to develop and implement healthy snack and beverage vending standards. Concurrently, Get Healthy Philly was implementing a variety of strategies targeting healthier eating in Philadelphia. These included a multimedia campaign to decrease sugary drink consumption, working with PDPH's Environmental Health Services Division to enforce Philadelphia's menu labelling ordinance (enacted in 2008), the Philly Food Bucks programme offering SNAP (Supplemental Nutrition Assistance Program) incentives for fruits and vegetables at farmers' markets, and a healthy corner store initiative in over 630 corner stores in Philadelphia ${ }^{(20,21)}$.

Healthy snack and beverage standards were included in the centralized City-wide vending contract and required: (i) two-thirds of items to meet healthy nutrition standards; (ii) smaller portion sizes for sugary drinks (12 ounces $(355 \mathrm{ml})$ instead of 20 ounces $(590 \mathrm{ml})$ ); (iii) prominent placement of healthy items; (iv) competitive pricing of healthy items; and (v) energy (calorie) labelling on machines. For beverage vending machines, the product featured on the machine 'wrap' (the image covering the actual surface of the machine) needed to meet the healthy standards and a small promotional sign reading 'Here's to your health!' pointed out healthy changes in offerings. For snack vending machines, healthy items were highlighted by green stickers or greencoloured prongs. There were no small promotional signs placed on snack vending machines. The standards are outlined more specifically in Table 1 . Standards were developed by a PDPH-registered dietitian and based on the Dietary
Guidelines for Americans 2010. Feedback was solicited from City departments, particularly on the types of products chosen to meet the standards. For beverages, 'healthy' options included water, non-caloric drinks and $100 \%$ juice. For snacks, healthy items included those with $\leq 250 \mathrm{kcal}$ $(\leq 1046 \mathrm{~kJ}), \leq 3 \mathrm{~g}$ saturated fat/serving, $\leq 7 \mathrm{~g}$ total fat/serving and $\leq 230 \mathrm{mg} \mathrm{Na} /$ serving. At least one snack item had to meet the above criteria and also have $\geq 5 \mathrm{~g}$ fibre/serving. Common snacks meeting healthy criteria included: $100 \mathrm{kcal}(418 \mathrm{~kJ})$ snack packs, fruit snacks, baked chips, granola bars and unsalted trail mixes.

From machine conversion periods onwards, healthy beverages were sold for between \$US 1.00 (12-ounce $(355 \mathrm{ml})$ non-caloric drink) and \$US 1.50 (20-ounce $(590 \mathrm{ml})$ water, 10 -ounce $(296 \mathrm{ml}) 100 \%$ juice $)$ and less healthy beverages generally sold for \$US 1.00 per 12 -ounce can. Therefore, the absolute price was higher for certain healthy beverages but the price per-ounce was lower for water than for sugary drinks. The average price for both healthy and less healthy snacks was \$US 0.92; however, the range of prices for healthy snacks was wider at \$US 0.65 to \$US 2.00 for healthy snacks $v$. \$US 0.75 to \$US 1.25 for less healthy snacks.

The healthy standards were implemented during 2011 for all beverage machines and 2012 for all snack machines. As part of the contractual agreement between the City and the vendor, planograms outlining products and their placement within machines were submitted to PDPH for recommendations and approval. PDPH staff reviewed the planograms to ensure that the correct mix of healthy $v$. less healthy options and prominent placements of healthy options were included.

Most machines included in the present study were located in police and fire stations/offices (23\%, $n$ 90), large office buildings $(20 \%, n$ 80) and correctional facilities (18\%, $n$ 71). Municipal courts and associated offices, including the offices of the district attorney, contained $13 \%(n 50)$ of the machines. The remaining machines were located in recreation centres $(5 \%, n 18)$, libraries $(2 \%, n 6)$ and other City-owned property (20\%, $n$ 81) such as parking garages and utility facilities.

\section{Vending data and analyses}

At the time of the study the City had 260 beverage vending machines and 130 snack vending machines. The vendor provided monthly sales data to PDPH from January 2010 to June 2013 as part of its contractual requirement. While all beverage vending machines fell under the healthy vending contract, 140 of those machines were sub-contracted to an outside vendor who was not able to provide sales data. Therefore, the current study reported on data from approximately 120 beverage and 130 snack vending machines.

Snack vending data were available for January 2011 through June 2013 and included item sales totals per machine per month and the sales price (in \$US) of items during that month, allowing for determination of revenue 
Table 1 Philadelphia Department of Public Health beverage and snack vending standards

\begin{tabular}{cl}
\hline & Beverages \\
\hline $\begin{array}{c}\text { Nutrition standards required } \\
\text { for } 65 \% \text { of machines }\end{array}$ & $\begin{array}{c}\text { Water, } 100 \% \text { juice and non-caloric drinks may be } \\
\text { considered healthy choices }\end{array}$
\end{tabular}

Snacks

\begin{tabular}{|c|c|}
\hline Portion size & $\begin{array}{l}\text { Sugar-sweetened beverages must be limited to } \\
12 \text { ounces ( } 355 \mathrm{ml}) \text { and may not be considered } \\
\text { healthy choices }\end{array}$ \\
\hline Placement & $\begin{array}{l}\text { Healthy beverages must be placed in the position } \\
\text { with the highest selling potential }\end{array}$ \\
\hline Promotion & $\begin{array}{l}\text { Only water or } 100 \% \text { juice can be featured on the } \\
\text { machine wrap }\end{array}$ \\
\hline Price & $\begin{array}{l}\text { Pricing models should promote healthy choices } \\
\text { by establishing lower prices for water relative to } \\
\text { soda and other sugar-sweetened beverages. } \\
20 \text {-ounce ( } 590 \mathrm{ml} \text { ) water remained } \$ U S 1.50 \text {. } \\
\text { Soft drinks (regular and diet) shifted from } \$ U S \\
1.50 \text { per } 20 \text {-ounce }(590 \mathrm{ml} \text { ) bottle to } \$ \text { US } 1.00 \\
\text { per } 12 \text {-ounce }(355 \mathrm{ml}) \text { can. } 100 \% \text { juice sold } \\
\text { at } \$ \text { US } 1.50 \text { per } 10 \text {-ounce }(296 \mathrm{ml}) \text { bottle }\end{array}$ \\
\hline Labelling & $\begin{array}{l}\text { The total energy (calorie) content for each item } \\
\text { must be displayed clearly and conspicuously }\end{array}$ \\
\hline
\end{tabular}

Required criteria: energy, $\leq 250 \mathrm{kcal}(\leq 1046 \mathrm{~kJ})$; saturated fat, $\leq 3 \mathrm{~g} /$ serving; total fat, $\leq 7 \mathrm{~g} /$ serving; $\mathrm{Na}, \leq 230 \mathrm{mg} /$ serving. There must be at least one high-fibre item ( $\geq 5 \mathrm{~g} /$ serving) also meeting above criteria. Recommended criteria: trans fat, $0 \mathrm{~g}$; sugar, $\leq 18 \mathrm{~g} /$ serving, excluding fresh and dried fruits and vegetables and fruit packaged in its own juice or water; at least five items should contain $10-19 \%$ of daily value for vitamins $\mathrm{A}, \mathrm{C}, \mathrm{E}, \mathrm{Ca}$ or $\mathrm{Fe}$

Items that meet the healthy snack criteria must be placed in the position with the highest selling potential

Only healthy snacks can be advertised on the machine or promoted through specials, games, giveaways and deals

The price of healthy snacks must not exceed the price of other options

The total energy (calorie) content for each item must be displayed clearly and conspicuously. Items with high fibre or a good source of vitamins or minerals must be labelled as such clearly and conspicuously

Standards were implemented in City of Philadelphia vending machines during 2011 for beverages and 2012 for snacks. The Philadelphia Department of Public Health revised the vending standards in 2016. Amendments include: healthy snacks may have no more than $1 \mathrm{~g}$ saturated fat/serving (except snacks containing only nuts or seeds); the previously recommended criterion on sugar was made required (healthy snacks must have no more than $18 \mathrm{~g}$ sugar/serving). Additions: $100 \%$ of snack items must have $0 \mathrm{~g}$ trans fats and no more than $230 \mathrm{mg} \mathrm{Na} /$ serving.

from the vendor-provided data. For all snack analyses, 2011 served as baseline, 2012 as the conversion period and 2013 as post-conversion. During the conversion period machines were transitioned to meet the healthy vending standards on a rolling basis, so the percentage of machines meeting the healthy standards changed over this time period.

There were two sources of data for beverage analyses, which were reported to different City departments. First, for data on sales volume, the vendor provided categorized item sales totals per machine per month to PDPH, but the data did not include item prices. Second, for revenue data, the vendor provided monthly revenue per machine to the City of Philadelphia Accounting Bureau. Data on sales volume were available for the full study period, January 2010 through June 2013. Data on healthy $v$. unhealthy beverage types were available beginning January 2011, and revenue data were not available for 2013. For beverage analyses, 2010 served as baseline, 2011 as conversion, 2012 as postconversion year 1 and 2013 as post-conversion year 2. Only the first seven months were available for post-conversion year 2 (2013) for beverage sales volume analysis.

Outcomes of interest for beverages and snacks included the proportion of sales attributable to healthy items; sales volume of healthy, less healthy and total units sold; and revenue from total units sold. All outcomes are presented as monthly average sales per machine. Vending units were considered 'healthy' if they met the required criteria outlined in Table 1 and described above. Water units were considered separately from other healthy beverages because of water's relative health benefits ${ }^{(22-24)}$. One-way ANOVA tests were conducted on each outcome of interest to determine significant differences in sales across intervention periods. When significant differences occurred across periods, post hoc tests were conducted, using Tukey's honest significant difference test, to determine between-group differences. Additionally, Levene's test for homogeneity of variance was conducted for each outcome of interest; where the test indicated unequal variance, we presented Welch's $F$ and associated degrees of freedom and $P$ values and results of Games-Howell post hoc tests. Data analysis was conducted using R software version 3.3.1 and PASW Statistics version 18.

\section{Results}

\section{Snacks}

Proportion of healthy v. less healthy sales

At baseline, the proportion of snack sales attributable to healthy snacks was $8 \%$, and at post-conversion healthy snacks accounted for $40 \%$ of total snack sales (Fig. 1). 


\section{Sales volume and revenue}

Sales volume of snacks across study time periods is reported in Table 2. On average, sales of healthy snacks were $323 \%$ higher post-conversion compared with baseline $(162.5 v$. 38.4 items sold per machine per month, respectively) and less healthy snack sales were $47 \%$ lower (239.6 at post-conversion $v .448 .7$ items sold per machine per month at baseline). Total snack sales were $17 \%$ lower at post-conversion compared with baseline (402.1 v. 486.8 items sold per machine per month, respectively).

Revenue data based on the sales price of snack items sold, provided to PDPH by the vendor, showed that on average revenue from snack machines was significantly lower at post-conversion compared with baseline (\$US $415.70 v$. \$468.30 per machine per month; $F=5.4$, $\mathrm{df}=4680, P=0 \cdot 004)$.

\section{Beverages}

Proportion of healthy v. less healthy sales

The proportion of total beverage sales attributable to healthy beverages was 10 percentage points higher two years post-conversion than during the conversion time period (46v. 36\%, respectively; Fig. 2).

\section{Sales volume and revenue}

Sales of healthy beverages were 33\% higher two years after conversion than during the conversion period

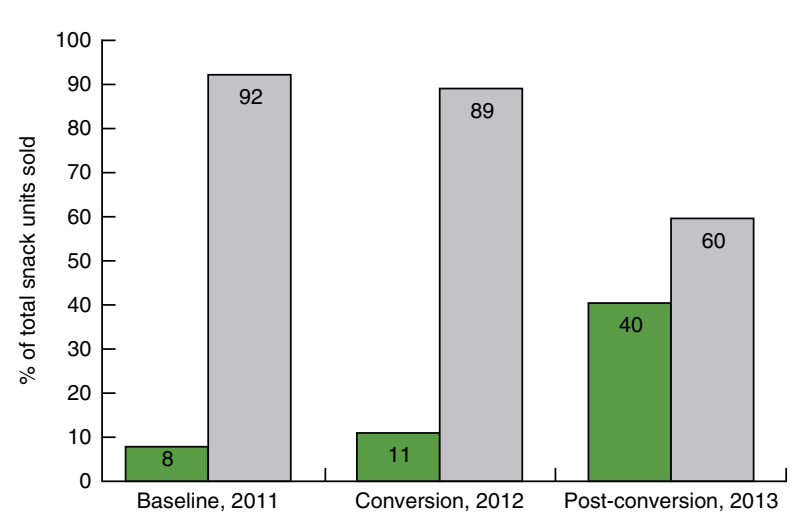

Fig. 1 Proportion of healthy ( $\square$ ) and less healthy ( $\square$ ) snacks units sold as a percentage of total units sold by study period for City of Philadelphia snack vending machines, 2011-2013
(90.6 v. 68.2 items sold per machine per month, respectively). Water sales, which were included in healthy beverage sales, were also higher two years after conversion $(35.5 v .25 \cdot 0$ items sold per machine per month during the conversion period). Less healthy beverages sales were $10 \%$ lower two years after conversion $(119 \cdot 0 v$. to $132 \cdot 1$ items sold per machine per month during the conversion period), but the change was non-significant. There was no significant change in total beverage sales from baseline to two years post-conversion (213.2 v. 209.6 items sold per machine per month, respectively; see Table 3 for more details).

Revenue data, provided to the City of Philadelphia Accounting Bureau by the vendor, showed that on average revenue from beverage machines was significantly lower two years post-conversion compared with baseline (\$US 270.70 v. \$344.00 per machine per month; $F=34.7$, df $=4570 \cdot 1, P<0 \cdot 001)$.

\section{Discussion}

Results from the current study show higher sales for healthy items and lower sales for less healthy items following the implementation of employer-wide vending standards affecting product mix, placement, promotion, price and portion size. The total sales volume of snacks was lower after machines were converted to meet the

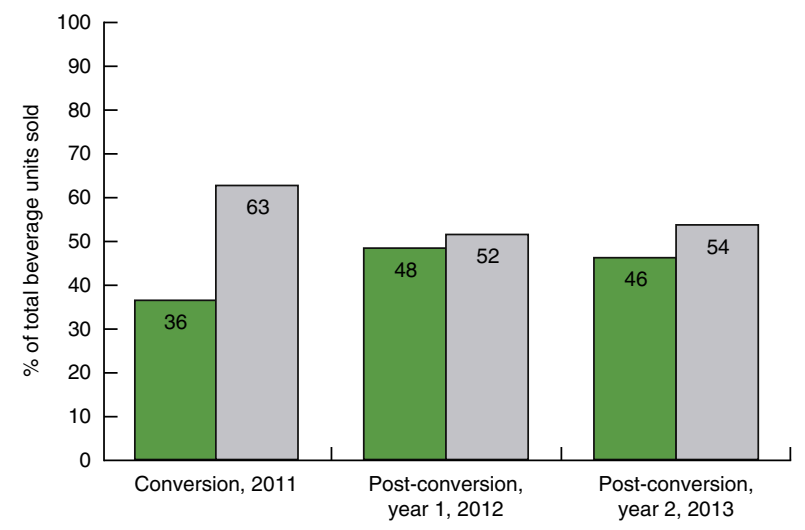

Fig. 2 Proportion of healthy ( $\square$ ) and less healthy ( $\square$ ) beverage units sold as a percentage of total units sold by study period for City of Philadelphia beverage vending machines, 2011-2013

Table 2 Monthly sales volume (units per machine per month)* for snack vending machines covered by the City of Philadelphia centralized vending contract, 2011-2013

\begin{tabular}{|c|c|c|c|c|c|c|c|c|c|}
\hline & \multicolumn{2}{|c|}{$\begin{array}{l}\text { Baseline, } 2011 \\
\quad(n 133)\end{array}$} & \multicolumn{2}{|c|}{$\begin{array}{c}\text { Conversiont, } 2012 \\
(n \text { 130) }\end{array}$} & \multicolumn{2}{|c|}{$\begin{array}{l}\text { Post-conversion, } 2013 \\
\text { ( } n \text { 127) }\end{array}$} & \multirow[b]{2}{*}{$F$} & \multirow[b]{2}{*}{ df } & \multirow[b]{2}{*}{$P$ value } \\
\hline & Mean & SE & Mean & SE & Mean & SE & & & \\
\hline Healthy & 38.4 & $1 \cdot 3$ & $51 \cdot 2^{\mathrm{A}}$ & $2 \cdot 1$ & $162 \cdot 5^{\mathrm{A}, \mathrm{B}}$ & $4 \cdot 8$ & 319.5 & $2675 \cdot 2$ & $<0.001$ \\
\hline Less healthy & $448 \cdot 7$ & $12 \cdot 0$ & $416 \cdot 6$ & $12 \cdot 1$ & $239 \cdot 6^{\mathrm{A}, \mathrm{B}}$ & $7 \cdot 1$ & $153 \cdot 7$ & 2917.9 & $<0.001$ \\
\hline Total & $486 \cdot 8$ & 13.1 & $467 \cdot 8$ & $13 \cdot 2$ & $402 \cdot 1^{\mathrm{A}, \mathrm{B}}$ & 11.6 & $13 \cdot 3$ & 3112.9 & $<0.001$ \\
\hline
\end{tabular}

A Significantly different from 2011; ${ }^{\mathrm{B}}$ significantly different from $2012(P<0.05)$.

*Data were provided by the contracted vendor.

†During 2012, City snack vending machines were converted to meet the new Healthy Vending Standards on a rolling basis. 
Table 3 Monthly sales volume (units per machine per month) ${ }^{\star}$ for beverage vending machines covered by the City of Philadelphia centralized vending contract, 2010-2013

\begin{tabular}{|c|c|c|c|c|c|c|c|c|c|c|c|}
\hline & \multicolumn{2}{|c|}{$\begin{array}{l}\text { Baseline, } 2010 \\
\quad(n \text { 133) }\end{array}$} & \multicolumn{2}{|c|}{$\begin{array}{l}\text { Conversiont, } 2011 \\
\text { (n 128) }\end{array}$} & \multicolumn{2}{|c|}{$\begin{array}{l}\text { Post-conversion, year 1, } 2012 \\
\text { (n 118) }\end{array}$} & \multicolumn{2}{|c|}{$\begin{array}{l}\text { Post-conversion, year 2, } 2013 \\
(n 115)\end{array}$} & \multirow[b]{2}{*}{$F$} & \multirow[b]{2}{*}{$\mathrm{df}$} & \multirow[b]{2}{*}{$P$ value } \\
\hline & Mean & SE & Mean & $\mathrm{SE}$ & Mean & $\mathrm{SE}$ & Mean & SE & & & \\
\hline Healthy $\ddagger$ & - & - & 68.2 & 1.8 & $96 \cdot 8^{\mathrm{B}}$ & $2 \cdot 4$ & $90 \cdot 6^{\mathrm{B}}$ & $3 \cdot 2$ & $51 \cdot 2$ & $1990 \cdot 4$ & $<0.001$ \\
\hline Water & - & - & $25 \cdot 0$ & 0.9 & $34.0^{\mathrm{B}}$ & $1 \cdot 1$ & $35 \cdot 5^{\mathrm{B}}$ & 1.6 & $27 \cdot 1$ & 1957.9 & $<0.001$ \\
\hline Less healthy & - & - & $132 \cdot 1$ & 4.0 & $120 \cdot 0$ & $3 \cdot 8$ & $119 \cdot 0$ & 4.8 & 3.3 & 3751 & 0.0386 \\
\hline Total & $213 \cdot 2$ & 5.5 & 200.5 & $5 \cdot 3$ & 216.9 & $5 \cdot 8$ & 209.6 & $7 \cdot 6$ & 1.6 & 5340 & 0.191 \\
\hline
\end{tabular}

${ }^{\text {A }}$ Significantly different from $2010 ;{ }^{B}$ significantly different from 2011 ; ${ }^{C}$ significantly different from $2012(P<0.05)$.

*Data were provided by the contracted vendor.

†During 2011, City beverage vending machines were converted to meet the new Healthy Vending Standards on a rolling basis. †Healthy units include water units.

healthy standards and there was no change in the sales volume of total beverages. Such changes suggest there was a previously unmet demand for healthy products and/or that the convenience afforded by the machines was greater than consumers' preferences for less healthy items. Regardless of the reason, the public health benefit of shifting a greater percentage of sales to healthy products remains.

The proportion of sales attributable to healthy items was higher after the implementation of the Philadelphia Healthy Vending Standards and at the final year of measurement was $40 \%$ for healthy snacks and $46 \%$ for healthy beverages. This confirms results from previous research on healthy vending initiatives conducted in worksite and school settings ${ }^{(12-17)}$. The proportion of healthy sales reached has varied widely across these studies. This range could reflect differences in multiple intervention characteristics, including the setting (schools, bus garages, parks), the mix of healthy and less healthy products (including complete replacement), supplemental pricing and promotional strategies (discounts on healthy items, signage), and the nature of the comparison group (control $v$. intervention(s), pre-/post-implementation comparison). We required that $65 \%$ of items meet healthy criteria, energy labelling, small promotional signs for beverage machines, and placement of a green sticker or green prongs to identify healthy snacks. A previous experimental study with very similar conditions to the present study (50\% healthy products, energy labelling and small promotional signage on the machine) found that $45 \%$ of snacks sold met their healthy criteria (lower in energy) ${ }^{(14)}$. Studies have shown an independent positive relationship between availability of healthy items and higher sales of those items ${ }^{(14-16,25)}$. Price reductions for healthy options $^{(12,15,17,25,26)}$ and product labels paired with additional promotional signage ${ }^{(12-14,25)}$ have also been associated with increased sales of healthy items.

In the current study, total beverage sales remained stable over the study period, but total snack sales were $17 \%$ lower after the standards were implemented. There are several strategies to maintain sales, not used in the current study, that have been used successfully in other studies. One approach is to incorporate pricing and promotional strategies around the items themselves. Competitive pricing of healthy items was required by the Philadelphia Healthy Vending Standards, but there were no price reductions of healthy items relative to less healthy items. Price discounts for healthy items may allow for increases in healthy snack sales while maintaining sales volume and revenue ${ }^{(12,15,25,26)}$. The CHIPS study found price reductions were significantly associated with sales of low-fat snacks, and the larger the reduction (between none, $10 \%, 25 \%$ and $50 \%$ ) the larger the associated increase in low-fat snack sales ${ }^{(12)}$. Importantly, the CHIPS study also analysed sales volume and profit as outcomes and found at a $50 \%$ price reduction of low-fat snacks that: low-fat snack sales were highest (21\% of snacks sold), sales volume was significantly higher than all other conditions and profits were unaffected ${ }^{(12)}$. As the authors note in that study, a higher sales volume would be desirable only if the foods purchased were of high nutritional benefit, such as fresh vegetables and water ${ }^{(12,25)}$.

Previous studies have implemented alternative combinations of promotional and informational materials. Additional motivational signage could have improved sales $^{(20)}$. Also, three-tiered labelling schemes have been used successfully in vending interventions without affecting sales ${ }^{(15,27)}$. Furthermore, labelling and promotion for healthy items could have benefits beyond the immediate point-of-purchase decision by influencing social norms ${ }^{(17)}$. Early taste-testing of healthy products may have also been useful $^{(6)}$; we did this two years into implementation.

Options could be considered to mitigate potential losses in revenue following the implementation of healthy vending standards. Revenue was a concern for many City departments who receive commission funds from vending machine sales (as a percentage of revenue defined by contract). Revenue was lower for snacks (11\%) and beverages (21\%) after the implementation of the standards. The change in revenue for snacks closely mirrored the change in total snack sales, and the strategies described above could help to sustain snack sales while increasing the proportion of healthy snacks sold. For beverages, where there was no change in total sales 
volume, the change in revenue was likely due to the fact that the price per unit for many products decreased by $33 \%$, from \$US 1.50 to \$US $1 \cdot 00$, because of the required reduction in portion size of sugary drinks from 20 ounces $(590 \mathrm{ml})$ to 12 ounces $(355 \mathrm{ml})$. From a public health perspective, the reduction in size of less healthy beverages magnified the impact of reduced sales of those beverages, since those still purchasing less healthy beverages were getting less energy in total. From the perspective of the contracted vendor, the implications are unclear. The authors do not know the cost of goods sold or other expenses faced by the vendor and have no way to estimate change, if any, in profits during the study period. It is possible that price increases for less healthy items could have boosted revenue, but this strategy has not been empirically studied.

Another possible approach to addressing revenue concerns is to take the opportunity to address other costs associated with vending machines, such as energy usage. In Philadelphia, the City recouped some revenue losses by requiring contracted vending agencies to implement energy efficiency measures within 12 months of the amended contract (energy retrofits; replacement of old machines with newer, more efficient ones), resulting in \$US 59115 of savings in the form of energy savings and utility rebates by the end of year $1^{(28)}$. Public and private agencies in other communities may be eligible for similar incentives.

The current study had several limitations. The study design was a limitation. The authors had no way to determine changes in profit that may have occurred over the study period, so were not able to address the feasibility of healthy vending standards from the vendor's perspective. There were a number of limitations directly related to the quality of the data the vendor was able to supply. Sales data were provided at the machine level, but there were no reliable unique identifiers for the machines over time. Because of this, we averaged monthly sales across all machines and were not able to take into consideration any differences in sales that may have existed between machine settings. Nor did we receive data indicating the exact date that a particular machine was converted to meet the standards. Sales data for beverages were only for the subset of machines (120 out of 260) directly controlled by the vendor, rather than via subcontract. Patterns may have differed across vendors. Additionally, for beverage data, there was no true baseline for comparing healthy, water and less healthy unit sales over time. The most likely effect of this limitation was to attenuate the magnitude of changes in sales over time. Furthermore, we did not assess compliance with the healthy vending standards. As 100\% compliance was likely not achieved, these findings represent the effects of real-world implementation of healthy vending standards. Lastly, the study did not assess whether vending users changed over time or users' eating habits outside the vending machines.

\section{Conclusion}

Following the implementation of employer-wide vending standards that required energy labelling and increased the availability of healthy snack and beverage vending items, sales of these items were significantly higher and sales of less healthy items were lower. Total sales volume of snacks was lower after implementation but total beverage sales remained stable. Entities receiving revenue-based commission payments from vending machines may face barriers due to revenue losses. Strategies modifying availability, promotion and pricing should be explored further to maximize health benefits while minimizing revenue impacts.

\section{Acknowledgements}

Financial support: Funding for this project was made possible in part by Cooperative Agreement \#1U58DP003557 from the Centers for Disease Control and Prevention, US Department of Health and Human Services. The Centers for Disease Control had no role in the design, analysis or writing of this article. The views expressed in this manuscript do not necessarily reflect the official policies of the US Department of Health and Human Services or the City of Philadelphia; nor does mention of trade names, commercial practices or organizations imply endorsement by the US Government. Conflict of interest: The authors report a grant from Centers for Disease Control and Prevention during the conduct of this study. Authorship: L.C. and G.M. worked on this project while employees of the Philadelphia Department of Public Health. G.M. and A.W. formulated the research questions, designed the study, carried out the study and provided substantial review on manuscript drafts. L.C. performed initial data cleaning and analysis and contributed to the manuscript drafts. M.L.P. performed most of the data analysis and manuscript writing. Ethics of human subject participation: Not applicable.

\section{References}

1. Novak NL \& Brownell KD (2012) Role of policy and government in the obesity epidemic. Circulation 126, 2345-2352.

2. Story M, Kaphingst KM, Robinson-O'Brien R et al. (2008) Creating healthy food and eating environments: policy and environmental approaches. Annu Rev Public Health 29, 253-272.

3. Byrd-Bredbenner C, Johnson M, Quick VM et al. (2012) Sweet and salty. An assessment of the snacks and beverages sold in vending machines on US post-secondary institution campuses. Appetite 58, 1143-1151.

4. Davee A-M, Blum JEW, Devore RL et al. (2005) The vending and à la carte policy intervention in Maine public high schools. Prev Chronic Dis 2, Spec. no., A14.

5. Davy BM, You W, Almeida F et al. (2014) Impact of individual and worksite environmental factors on water and 
sugar-sweetened beverage consumption among overweight employees. Prev Chronic Dis 11, E71.

6. Mason M, Zaganjor H, Bozlak CT et al. (2014) Working with community partners to implement and evaluate the Chicago Park District's 100 \% Healthier Snack Vending Initiative. Prev Chronic Dis 11, E135.

7. Cradock AL, Kenney EL, McHugh A et al. (2015) Evaluating the impact of the healthy beverage executive order for city agencies in Boston, Massachusetts, 2011-2013. Prev Chronic Dis 12, E147.

8. Lessard L, Poland M \& Trotter M (2014) Lessons learned from a healthful vending pilot program in Delaware State agency buildings, 2011-2012. Prev Chronic Dis 11, E143.

9. New York City Food Policy Division (2017) Food Policy Initiatives - Procurement. http://www1.nyc.gov/site/food policy/initiatives/procurement.page (accessed April 2017).

10. City and County of San Francisco Food Division (2017) San Francisco Healthy and Sustainable Food Policy. http://sfgov. org/sffood/san-francisco-healthy-and-sustainable-food-policy (accessed April 2017).

11. City of Annapolis Department of Recreation and Parks Health and Wellness (2017) Healthy Vending. https://www. annapolis.gov/382/Healthy-Vending (accessed April 2017).

12. French SA, Jeffery RW, Story $M$ et al. (2001) Pricing and promotion effects on low-fat vending snack purchases: the CHIPS study. Am J Public Health 91, 112-117.

13. Fiske A \& Cullen KW (2004) Effects of promotional materials on vending sales of low-fat items in teachers' lounges. $J \mathrm{Am}$ Diet Assoc 104, 90-93.

14. Wilbur CS, Zifferblatt SM, Pinsky JL et al. (1981) Healthy vending: a cooperative pilot research program to stimulate good health in the marketplace. Prev Med 10, 85-93.

15. Kocken PL, Eeuwijk J, Van Kesteren NMC et al. (2012) Promoting the purchase of low-calorie foods from school vending machines: a cluster-randomized controlled study. J Sch Health 82, 115-122.

16. Gorton D, Carter J, Cvjetan B et al. (2010) Healthier vending machines in workplaces: both possible and effective. $N Z$ Med J 123, 43-52.

17. French SA, Hannan PJ, Harnack LJ et al. (2010) Pricing and availability intervention in vending machines at four bus garages. J Occup Environ Med 52, Suppl. 1, S29-S33.
18. US Census Bureau (2017) US Census Bureau Quick Facts Philadelphia County, Pennsylvania. http://www.census. gov/quickfacts/table/PST045216/42101 (accessed May 2017).

19. Philadelphia Department of Public Health (2017) 2016 Community Health Assessment (CHA). Philadelphia, PA: City of Philadelphia; available at http://www.phila.gov/ health/pdfs/CommunityHealthAssessment2016.pdf

20. City of Philadelphia Department of Public Health (2012) Get Healthy Philly Healthy Eating and Active Living Annual Report, 2011-12. Philadelphia, PA: City of Philadelphia Department of Public Health.

21. City of Philadelphia Department of Public Health (2011) Get Healthy Philly Annual Report 2011. Philadelphia, PA: City of Philadelphia Department of Public Health.

22. Stookey JD, Constant F, Gardner CD et al. (2007) Replacing sweetened caloric beverages with drinking water is associated with lower energy intake. Obesity (Silver Spring) 15, 3013-3022.

23. Stookey JD, Constant F, Popkin BM et al. (2008) Drinking water is associated with weight loss in overweight dieting women independent of diet and activity. Obesity (Silver Spring) 16, 2481-2488.

24. Tate DF, Turner-McGrievy G, Lyons E et al. (2012) Replacing caloric beverages with water or diet beverages for weight loss in adults: main results of the Choose Healthy Options Consciously Everyday (CHOICE) randomized clinical trial. Am J Clin Nutr 95, 555-563.

25. Grech A \& Allman-Farinelli M (2015) A systematic literature review of nutrition interventions in vending machines that encourage consumers to make healthier choices: efficacy of vending machine interventions. Obes Rev 16, 1030-1041.

26. French SA, Jeffery RW, Story M et al. (1997) A pricing strategy to promote low-fat snack choices through vending machines. Am J Public Health 87, 849-851.

27. Brown MV, Flint M \& Fuqua J (2014) The effects of a nutrition education intervention on vending machine sales on a university campus. $J$ Am Coll Health 62, 512-516.

28. PECO - An Exelon Company (2015) PECO Smart Equipment Incentives. https://www.peco.com/Savings/ ProgramsandRebates/Business/Pages/PECOSmartEquipment Incentives.aspx (accessed February 2015). 